\section{Rhino conservation tactics}

SIR - Although African elephant populations are increasing as a result of the moratorium on the ivory trade begun in 1989, the signs are less encouraging for black rhinos, whose prodigious decline continues ${ }^{1}$. Efforts aimed at the conservation of Africa's black and white rhinos have increasingly taken three forms - translocation to safe reserves, attempts to halt the illicit market, and dehorning, a controversial procedure first tried in Namibia in 1989 (refs 2,3 ). Dehorning is still practiced there and it has been adopted in Zimbabwe on both species. The efficacy of this programme remains uncertain, although data gathered by my colleagues and me from a recent field study of black rhinos in Namibia's Kunene River Province and Etosha National Park offer some insights.

First, regeneration of rhino horn is rapid, averaging nearly 9 $\mathrm{cm}$ of total horn per animal per year (Fig. 1). Because the estimated black-market value of newly grown horns ranges from $\$ 1,775$ to $\$ 7,750$ on an average animal just 1 year after dehorning ${ }^{4}$ and removal costs about $\$ 1,400$ per animal, the price of annual horn pruning is exceeded by the horn's black-market value in just 10 months. It was also concluded in a recent modelling exercise that intensive horn harvesting must be adopted if rhinos are to remain valueless to poachers 5 .

Second, this finding is reinforced by new information on the choices of

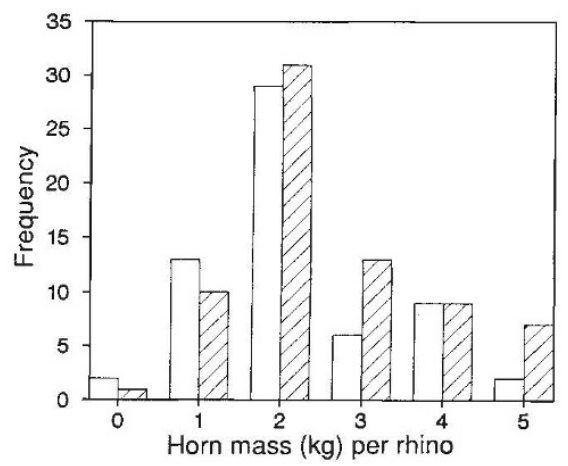

FIG. 2 Frequency distributions of the mass of horns (anterior and posterior combined) on adult and subadult black rhinos confiscated from poachers (open boxes) or on live rhinos (hatched boxes). Horn mass $(Y)$ of live rhinos was estimated photogrammetrically based on measurements from 104 confiscated horns, where $Y=15.49 X-0.21$ and $X$ is horn circumference times length $\left(r^{2}=\right.$ 0.83; $P<0.0001)$. Distributions of the poached and live samples do not differ (Kolmogorov-Smirnoff test; $D=0.444$ ).

poachers. If larger-horned rhinos were preferred trophies, then recently dehorned individuals would remain of low value. However, the similarity between mass categories of horns confiscated from poachers and those on live rhinos in extant, wild populations (Fig. 2)

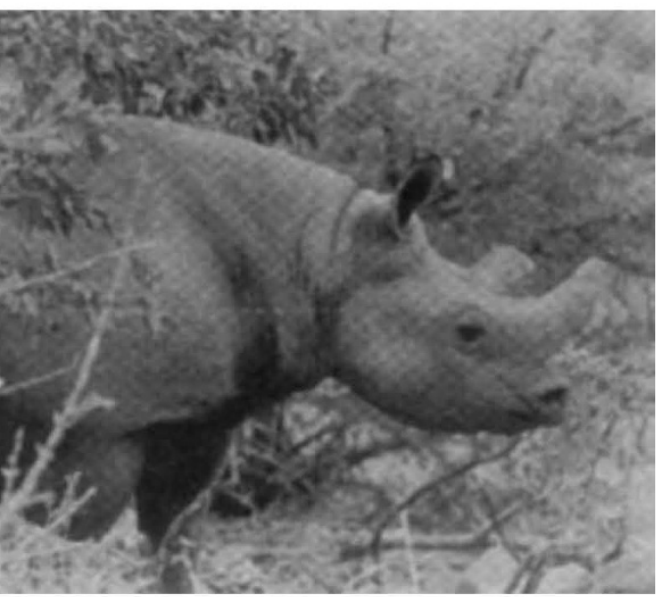

FIG. 1 Regrowth of horns in an adult black rhino emale 3 years after dehorning.

points to a lack of discrimination by poachers. This suggests that even rhinos with small horn nubs are vulnerable to poachers.

Third, although the claim made regularly by the popular media, that dehorning must be working since no hornless rhinos have been poached, seems encouraging, it is also true that horned Namibian black rhinos have not been poached either. In reality, it is impossible to conclude anything about the demographic effects of dehorning. From a behavioural perspective, maternal responsiveness to dangerous predators such as lions and spotted hyenas has less to do with horn size than to the ages of the young. Mothers of calves less than 18 months old flee about five times more often than when the calves are older (J. B. and C. Cunningham, unpublished data).

Although these results might dampen enthusiasm for dehorning, any definite conclusions would be premature. One unforeseen consequence of dehorning has been the massive and often sensational media coverage. Poachers may have simply moved elsewhere or be waiting for the interest to die down. And political actions such as Namibian independence, the removal of South African defence forces, or the cessation of civil strife involving Angola, Namibia and South Africa, may have contributed to a demise in poaching. Whatever the cause(s), involving local people in the search for realistic ways to maintain viable populations of Africa's rhinos remains the critical challenge.

\section{Joel Berger}

Program of Ecology, Evolution and

Conservation Biology,

University of Nevada,

Reno,

Nevada 89512, USA

1. Western D. Trends ecol Evol. 2, 343-346 (1987)

2. Leader-Williams, N. Nature $\mathbf{3 4 0}, 599-600$ (1989)

3. Lindeque, M. S. Afr. J. Sci. 86, 226-227 (1990).

4. Milliken, T. et al. Traffic Bull. 12, 17-21 (1991).

5. Milner-Gulland, E. J. et at. Proc. R. Soc. Lond. B249. 83-87 (1992).

\title{
A word in your protein
}

SIR - What is the longest word spelled out in the sequence of a protein in the protein sequence database ${ }^{1}$ using the one-letter code for amino acids? None of the extensive literature devoted to this problem $^{2-4}$ has taken a truly systematic approach; the longest word found to date contains only seven letters. We have matched the entire Oxford Unabridged English Dictionary (second edition, 20 volumes, 572,728,830 characters, with information content close to that of the human genome) against the entire SwissProt protein sequence database (version 23) ${ }^{5}$. Using the Patricia tree data structure ${ }^{1}$, the matching consumed only 23 minutes of computational time. We found two words with nine characters: "hidalgism" (the manner or practice of a hidalgo) entered the English dictionary via a citation from 1887, and appears at positions 247-355 of the integrase of bacteriophage lambda (acquisition number P03700). "Ensilists" (the plural of ensilist, one who preserves his crops by ensilage) entered the dictionary via a citation from 1883, and appears at positions 81-89 of the PRRB protein from Escherichia coli (acquisiton number P17222).

In addition to being the longest strings appearing simultaneously in the English and protein languages, these are also candidates for the most unusable pieces of information simultaneously in lexicography and in biochemistry. Their discovery does, however, demonstrate the power of these data structures in handling large amounts of information.

\section{Gaston H. Gonnet}

\section{Steven A. Benner}

Institute for Scientific Computation, and Institute for Organic Chemistry,

ETH, Zurich, $\mathrm{CH}-8092$ Switzerland

\footnotetext{
1. Gonnet, G. H., Cohen, M. A. \& Benner, S. A. Science 256, 1443-1445 (1992).

Price, N. C. Trends biochem. Sci. 12, 349 (1987)

3. Purton, M. Trends biochem Sci 13, 48 (1988).

Jimenez, A. Trends biochem. Sci 14, 14 (1989)

Bairoch, A. \& Boeckmann, B. Nucleic Acids Res. 20. 2019-2022 (1992)
} 